\section{AS PRÁTICAS CIRCENSES NO "TEAR" DA FORMAÇÃO INICIAL EM EDUCAÇÃO FÍSICA: NOVAS TESSITURAS PARA ALÉM DA LONA}

\author{
CIRCUS PRACTICES IN THE "LOOM" OF INITIAL TRAINING IN PHYSICAL \\ EDUCATION: NEW TEXTURES IN ADDITION TO THE CANVAS
}

LAS PRÁCTICAS CIRCENSES EN EL "TELAR" DE LA FORMACIÓN INICIAL EN EDUCACIÓN FÍSICA: NUEVAS TEXTURAS MÁS ALLÁ DE LA CARPA

Rita de Cassia Fernandes Miranda*, Eliana Ayoub**
Palavras-chave Educação Física. Currículo.

Circo.

\begin{abstract}
Resumo: Este artigo analisa os processos de implementação das práticas circenses na formação inicial em Educação Física em duas Instituições de Ensino Superior do Estado de São Paulo. Para isso, entrelaçou-se a análise documental dos projetos políticopedagógicos das instituições e dos programas das disciplinas relacionadas à temática circense às entrevistas narrativas com professores, gestores e alunos. Constatou-se que os processos investigados foram sedimentados no contexto de intensas histórias de mobilizações e embates, de trajetórias de pesquisa na busca pela construção de sólidos conhecimentos para além dos limites que os tempos e espaços institucionais impõem.
\end{abstract}

Abstract: This paper analyzes the processes of implementation of circus practices in initial training in Physical Education at higher education institutions in the State of São Paulo, Brazil. The document analysis of the political-pedagogic projects of the institutions and programs of disciplines related to the subject of circus were interwoven to narrative interviews with teachers, managers and students. The processes investigated were found to be based on intense stories of mobilizations and clashes, on research trajectories seeking to build solid knowledge beyond the limits imposed by institutional times and spaces.

Resumen: Este artículo analiza los procesos de implementación de las prácticas circenses en la formación inicial en Educación Física en dos instituciones de educación superior del Estado de São Paulo, en Brasil. Para ello, se entrelazaron el análisis documental del proyecto político pedagógico de las instituciones y los programas de las disciplinas relacionadas con la temática circense y las entrevistas narrativas con profesores, administradores y alumnos. Se constató que los procesos investigados resultan de intensas historias de movilizaciones y enfrentamientos, de trayectorias de investigación en buscando construir sólidos conocimientos más allá de los límites que imponen los tiempos y espacios institucionales.
* Universidade Federal de Uberlândia (UFB). Uberlândia, MG, Brasil. E-mail: rifernandes36@gmail.com

** Universidade Estadual de Campinas (UNICAMP). Campinas, SP, Brasil. E-mail: ayoubeliana@gmail.com

Recebido em: 29-04-2015 Aprovado em: 14-06-2015 (c) (1) (8) Licence 


\section{INICIANDO NOSSO “NÚMERO”}

A polissemia das práticas circenses ${ }^{1}$ em suas diferentes expressões ao longo da história leva a refletir sobre diversas possibilidades formativas ainda pouco perscrutadas. $\mathrm{Na}$ contemporaneidade, especificamente na Educação Física, abre-se um amplo potencial pedagógico que instiga o aprofundamento das investigações. De modo semelhante, ao serem observadas com maior critério as relações entre essas áreas, constata-se intenso diálogo, e também inúmeras tensões e contradições historicamente constituídas ao longo dos séculos XIX e XX (SOARES, 2002, 2009, HAUFFE; GÓIS JUNIOR, 2014); um conjunto de significados do corpo e do gesto singulares às práticas circenses debatidos na Educação Física; além da pluralidade dessas manifestações em diferentes cenários.

$O$ crescimento da produção acadêmica no que se refere às práticas circenses no contexto da Educação Física, em especial a partir dos anos de 1990 (BORTOLETO, 2011, ONTANÓN; DUPRAT; BORTOLETO, 2012), permite visualizar múltiplas formas de aproximação ao universo circense. No cenário escolar, as práticas circenses foram analisadas por Duprat (2007) e Ontañón (2012), fazendo parte também das Diretrizes Curriculares da Educação Básica do Estado do

Paraná (PARANÁ, 2008); na área social, diferentes propostas abordam o seu desenvolvimento no âmbito socioeducativo para jovens em situação de risco social (MCCUTCHEON, 2003, BOLTON, 2004); na promoção da saúde (SANTOS et al., 2012, TUCUNDUVA; PELANDA, 2012); no contexto do lazer os jogos inspirados nas práticas circenses promovendo a ludicidade (SILVA, C. L., 2009, BORTOLETO; PINHEIRO; PRODÓCIMO, 2011); na formação inicial em Educação Física compondo a matriz curricular de alguns cursos (BORTOLETO; CELANTE, 2011, FERNANDES, 2014) e, por fim, na formação continuada e na extensão universitária² (ABRAHÃO, 2011).

Além desses exemplos, pelo menos dois programas do Governo Federal, um deles vinculado ao Ministério do Esporte, chamado "Programa Segundo Tempo"3, e outro ligado ao Ministério da Educação, o "Programa Mais Educação", têm fomentado diversas atividades educativas com acompanhamento pedagógico e, dentre elas, as práticas circenses se fazem presentes, o que motivou algumas empresas a comercializarem materiais e equipamentos na forma de um "kit circense" já estruturado para o desenvolvimento das ações educativas desses programas.

A despeito das possibilidades aventadas, o trabalho de Duprat e Darido (2011) arbitrou, por meio de um levantamento de propostas curriculares de ensino fundamental de nove estados

1 Apesar da predominância da terminologia "atividades circenses" no campo, preferimos tratá-las como "práticas circenses", que, evidentemente, não são aquelas transferidas de modo linear do âmbito circense profissional para outros cenários educacionais, mas sim na condição de manifestações que podem ser tematizadas considerando diferentes objetivos. Inspiramo-nos nas reflexões de Silva e Damiani (2005) sobre as expressões "atividade física" e "prática corporal", para fazermos esse paralelo entre "atividades circenses" e "práticas circenses". Para as autoras, "prática corporal" configura-se como uma expressão que "[...] mostra adequadamente o sentido de construção cultural e linguagem presentes nas diferentes formas de expressão corporal" (SILVA; DAMIANI, 2005, p. 24).

2 COSTA, Ana C. P.; TIAEN, Marcos S.; SAMBUGARI, Marcia R. N. O circo na UFMS/CPAN: a formação de professores e acadêmicos como multiplicadores de arte circense nas instituições escolares e não escolares. In: ENCONTRO DE EXTENSÃO UNIVERSITÁRIA DA UFMS, 3., Campo Grande, 2008. Anais... p. 83.

3 Considerado programa estratégico do Governo Federal, o "Programa Segundo Tempo" visa democratizar o acesso à prática e à cultura do esporte educacional a fim de promover o desenvolvimento integral de crianças, adolescentes e jovens como fator de formação da cidadania e melhoria da qualidade de vida, prioritariamente daqueles que se encontram em áreas de vulnerabilidade social (BRASIL, 2011).

40 "Programa Mais Educação" integra as ações do Plano de Desenvolvimento da Educação (PDE) e constitui-se como estratégia do Ministério da Educação para induzir a ampliação da jornada escolar e a organização curricular na perspectiva da Educação Integral. As escolas das redes públicas de ensino estaduais, municipais e do Distrito Federal podem fazer adesão ao Programa, optando por atividades diversificadas com acompanhamento pedagógico. Para maiores esclarecimentos: <http://portal.mec.gov.br/index.php?option=com content\&view=article\&id=16690\&|temid $=1115>$ 
brasileiros, que apenas duas delas trazem as práticas circenses como conteúdo curricular. Ora, identifica-se a expansão desses conhecimentos em diferentes contextos, entretanto as propostas curriculares brasileiras não os abordam. Visualiza-se um volume significativo de relatos de experiência com enfoque na escola, mas a universidade, em especial a formação inicial em Educação Física, debate raramente essa temática e pouco contribui para a sua contextualização. A situação constatada indicia certo descompasso entre os documentos oficiais e o cotidiano dos diferentes âmbitos de atuação da Educação Física? Como isso tem acontecido fora do Brasil? Trabalhos como os de Fodella (2000), Invernó (2003) e Price (2012) permitem supor que sim.

Em estudos anteriores, (FERNANDES, 2013, FERNANDES; EHRENBERG, 2014, ${ }^{5}$ FERNANDES, 2014), constatou-se que apenas um número reduzido de Instituições de Ensino Superior (IES) parecem estar mais atentas ao quadro exposto. Nos casos investigados no Estado de São Paulo, a participação ativa e efetiva dos docentes e discentes nas ações extensionistas de ensino e de pesquisa propiciou visibilidade e possibilidades de construção de conhecimentos advindos das práticas circenses, contribuindo para sua legitimação.

Nesse limiar, observa-se uma temática relevante para o campo, mas poucas orientações didático-pedagógicas e metodológicas sobre o seu desenvolvimento na formação inicial, além do risco de tratá-las de forma fragmentada, assistemática e instrumental. Esse problema pode influenciar desde a falta de procedimentos de segurança nas aulas, até o uso de técnicas circenses sem coerência com seus princípios e objetivos. Por isso, defende-se a relevância do encaminhamento de propostas que discutam a presença das práticas circenses nos currículos, de forma a contemplar a diversidade de possibilidades do universo da cultura corporal como patrimônio da humanidade a ser reconhecido, valorizado e ressignificado.

Contudo, não se desconsideram as relações de poder que sedimentam hierarquizações deconhecimentos, valorizando alguns e invisibilizando outros(SILVA, T. T., 2007). A problemática exposta pelo autor sugere, mais uma vez, o território de embates que configura o currículo, 0 qual se entende que deva ser constituído coletivamente a partir de profundas análises sobre as especificidades dos campos de atuação profissional, portanto, reconstruído e avaliado continuamente por seus atores.

Qualquer decisão curricular é sempre uma ação política que ensina também pelo que silencia e negligencia, posicionando os sujeitos no interior das culturas e pondo em circulação diferentes discursos. Por isso, questionam-se quais os modelos de sociedade pretendidos pelos atuais currículos de formação inicial em Educação Física. E mais, os conhecimentos que são contemplados nos currículos lá estão a partir de quais interesses?

Verificou-se que alguns cursos superiores de Educação Física começam a se sensibilizar com os conhecimentos circenses que de fato estão assentados sobre as próprias raízes históricas do campo, argumento relevante para justificar sua inserção curricular (INVERNÓ, 2003, BORTOLETO, 2011).

Ao almejarem-se processos de construção curricular na formação inicial em que os protagonistas sejam respeitados, suas vozes ouvidas e as minorias acolhidas, a proposta em pauta, portanto, é considerar os diferentes conhecimentos da comunidade na qual a instituição

5 FERNANDES, Rita de C.; EHRENBERG, Monica C. As práticas corporais circenses na formação inicial em educação física: gestualidade, expressividade e inovação curricular em foco. In: ENCONTRO NACIONAL DE DIDÁTICA E PRÁTICA DE ENSINO, 17., 2014, Fortaleza. Anais.. 
educacional se insere. Não obstante, "o currículo é, como muitas outras, uma prática de atribuir significados, um discurso que constrói sentidos. Ele é, portanto, uma prática cultural" (LOPES; MACEDO, 2011, p. 203).

No bojo dessas discussões, o objetivo da pesquisa está voltado para a análise dos processos de implementação das práticas circenses na formação inicial em Educação Física, a partir de experiências curriculares concretas no âmbito do ensino, pesquisa e extensão em duas IES do Estado de São Paulo.

\section{AS PRÁTICAS CIRCENSES AQUI E ACOLÁ: OS CAMINHOS TRILHADOS NA PESQUISA}

Esta pesquisa de natureza qualitativo-descritiva foi realizada em duas IES do Estado de São Paulo, sendo uma universidade pública estadual (Instituição A) e a outra uma autarquia municipal com autonomia administrativa (Instituição B), com autorização de ambas para a realização da pesquisa ${ }^{6}$.

Ressalta-se que a escolha pelo aprofundamento e análise dos significados da implementação das práticas circenses nas referidas instituições refere-se ao fato de ter sido identificada a existência de práticas pedagógicas abordando tais manifestações, inseridas na matriz curricular desses cursos, desde 2006 na Instituição A e a partir de 2009 na Instituição B, conforme atesta a pesquisa de Bortoleto e Celante (2011), o que motivou a empreender reflexões críticas sobre os processos de implementação dessas práticas corporais.

Para tanto, entrelaçou-se a análise documental (LUDKE; ANDRÉ, 1986) do projeto político-pedagógico (PPP) da Instituição $A^{7}$, do Relatório Institucional (RI) do período de 2010 a 2012 da Instituição $B^{8}$ e dos programas das disciplinas ligadas à temática circense, à realização de entrevistas narrativas (FLICK 2009, JOVCHELOVITCH; BAUER, 2012). A Instituição B não disponibilizou seu PPP para a pesquisa argumentando que este estaria em reestruturação, cedendo apenas o Rl elaborado para fins de recredenciamento do curso.

Seguindo as recomendações de Kincheloe (2006) e Denzin e Lincoln (2006), a escolha dos participantes não foi aleatória. Buscou-se o equilíbrio quantitativo, estabelecendo na medida do possível a proporcionalidade entre os sujeitos situados em diferentes níveis da hierarquia administrativa e pedagógica das IES pesquisadas, a fim de que diferentes vozes fossem representadas.

Para Jovchelovicht e Bauer (2012, p. 104) o "envolvimento direto e imediato nas atividades centrais do evento que está sendo contado parece ser um fator importante na produção de narrativas". Portanto, foram priorizados sujeitos que de alguma forma tivessem exercido o contato mais estreito com essa temática, seja através de projetos de extensão, monitorias ou atividades afins.

Complementando o cenário delineado, foram obtidos junto aos docentes e com a coordenação dos cursos alguns contatos de alunos e professores, buscando a aceitação e inclusão destes como participantes da pesquisa a partir dos critérios já mencionados. As

6 A pesquisa foi aprovada junto ao Comitê de Ética em Pesquisa da Faculdade de Ciências Médicas da UNICAMP (parecer n. 374.524). Foi obrigatório o envio dos ofícios de autorização das IES.

7 INSTITUIÇÃO A. Projeto Político-Pedagógico. São Paulo, 2012.

8 INSTITUIÇÃO B. Relatório Institucional de 2010-2012. São Paulo, 2012. 
entrevistas foram previamente agendadas e realizadas entre agosto e outubro de 2013 , tendo sido gravadas com a autorização dos sujeitos e transcritas para fins de análise pelas próprias pesquisadoras. No início de cada entrevista, foi apresentado o Termo de Consentimento Livre e Esclarecido (TCLE), mantendo a confidencialidade quanto à identidade dos participantes, os quais são indicados na pesquisa por nomes fictícios escolhidos pelos próprios sujeitos.

Desse modo, foram entrevistados 13 participantes, dentre eles:

- dois coordenadores dos cursos de Educação Física, sendo um docente da Instituição A e outro da Instituição B;

- dois professores, sendo um docente da Instituição A e outro da Instituição B, responsáveis pela disciplina relacionada às práticas circenses nos cursos de Educação Física pesquisados;

- uma professora da Instituição A, ex-coordenadora de curso que acompanhou os primeiros projetos de extensão e trabalhos de conclusão de curso relacionados à temática;

- dois professores convidados, artistas profissionais, que ministraram aulas nas disciplinas e que acompanham o trabalho desenvolvido há mais de dois anos, sendo um de cada instituição;

- três alunos egressos, de ambos os sexos, maiores de idade, que cursaram as disciplinas ligadas às práticas circenses nas IES;

- três alunos regulares, de ambos os sexos, maiores de idade, que cursavam o último semestre dos cursos de Educação Física pesquisados à época da coleta, sendo dois alunos da Instituição A e um aluno da Instituição B.

Verificou-se que, do conjunto de participantes, três são mulheres e dez são homens. As idades dos docentes e gestores ficaram entre 22 e 47 anos e dos alunos regulares e egressos entre 22 e 33 anos. Além disso, no grupo dos docentes e gestores apenas um professor convidado está em formação inicial, enquanto os demais são mestres ou doutores. A maioria exerceu a docência no ensino superior por tempo significativo, mais de cinco anos, no período em que as entrevistas foram realizadas.

Posteriormente à transcrição das entrevistas, as quais foram conduzidas como situação de enunciação que reitera "a necessidade de buscar nas práticas discursivas o processo, 0 movimento, o sentido, fazendo com que a entrevista seja o lugar no qual se constroem possíveis versões da realidade" (ROCHA; DAHER; SANT'ANNA, 2004), os textos das transcrições foram enviados aos sujeitos por correio eletrônico, para que pudessem apreciá-los e acrescentar ou alterar alguma parte, caso desejassem. Apenas uma das entrevistas com um aluno egresso da Instituição A foi realizada a distância através de programa de voz, o que favoreceu uma forma diferente de interação através das novas tecnologias de comunicação, mas que acabou dificultando de certo modo a dinâmica devido à velocidade de conexão, corte da chamada ou de rede.

Outra questão que foi objeto de preocupação referiu-se às implicações das relações anteriores já vividas entre as pesquisadoras e alguns sujeitos da pesquisa, ao compartilhar espaços relativamente próximos de formação inicial e continuada. Nessa dinâmica, optou-se por considerar tais materiais de análise como parte de uma pesquisa que não é asséptica e tampouco neutra, pois abraça essa proximidade entre pesquisadores e sujeitos, lançando luz às diferentes visões de mundo que estão em jogo nas análises realizadas e suas condições de produção (DENZIN; LINCOLN, 2006). 


\section{OLHARES A PARTIR DAS ENTREVISTAS E DOCUMENTOS: DOS PERCURSOS INDIVIDUAIS ÀS TRAJETÓRIAS COLETIVAS}

Ao longo das entrevistas e da análise dos documentos, encharcadas pelos sentidos e significados postos em circulação através das vozes dos diferentes sujeitos, surgiram temas e questões que emergiam dos achados, sem, contudo, estarem estabelecidos a priori. Assim, neste texto será analisada a seguinte questão: de que forma e a partir de quais condições as práticas circenses foram implementadas nessas instituições?

Foi perceptível que, embora ambos os processos tenham ocorrido praticamente na mesma época, esses se deram de formas distintas, com objetivos e características bem particulares. Não se está propondo estabelecer comparações arbitrárias, mas analisar as experiências vividas naqueles contextos, ora identificando suas potencialidades, ora aprendendo com suas limitações, ora cotejando tais experiências com os pontos de vista dos autores em diálogo, ora sendo surpreendidos pelos modos de fazer desses docentes. Paisagens criativas que os sujeitos foram arquitetando ao longo de suas trajetórias.

Talvez seja interessante pensar tais processos situando dois momentos ou movimentos que, evidentemente, estão interligados e se desdobram em vários outros, mas se entende que seja relevante apontá-los. O primeiro momento configurou-se como uma inserção não institucionalizada, motivada principalmente pela demanda de grupos de alunos interessados nas práticas circenses ou mesmo pelo fato de já serem artistas com experiências construídas fora do contexto da faculdade. Percebeu-se que esses mesmos sujeitos mobilizaram-se para "serem vistos", buscando apoio nos docentes para a vivência e reflexão acerca dessas práticas corporais no ensino superior, inicialmente através dos projetos de extensão.

[...] os primeiros tecidos que foram colocados eram de garotas que faziam atividades circenses, não eram da faculdade. E eventualmente a gente via um pingente ali, uma menina subindo e descendo e aquilo chamava muita atenção. Aí se oficializou essa possibilidade. Hoje, a gente tem vários aéreos. (Rogério, docente responsável pela disciplina, Instituição B)

A professora E., que foi uma professora aqui da $F$. que entrou no começo dos anos 2000, apoiou alguns projetos de alunos que foram estudar, alguns TCCs em circo [...]. Nesse momento, eles (os docentes J. e B.) vão dando um suporte para os alunos desenvolverem as atividades extracurriculares de interesse. (Willybaldo, docente convidado, Instituição A)

Já um segundo momento sugeriu uma inserção mais pontual, institucionalizada por meio dos docentes responsáveis pelas disciplinas que, sensibilizados pela temática e impactados pelas suas próprias experiências profissionais e acadêmicas, bem como por considerarem a relevância e ao mesmo tempo a ausência de uma discussão contextualizada sobre tais conhecimentos na matriz curricular dos cursos, apresentaram projetos para sua implementação. Em ambos os casos foram criadas linhas de pesquisa e grupos de estudos contemplando esse tema, contribuindo para as ações ligadas ao ensino e à extensão.

Para os professores investigados haveria uma "lacuna a ser preenchida" nos currículos, especialmente com questões ligadas à expressão, à arte e ao gesto como formas de linguagem que quase sempre não eram abordadas, ou estavam presentes de forma diluída em outras disciplinas que, quando muito, tratavam de algumas manifestações folclóricas ligadas à dança ou à capoeira. 
$\mathrm{Na}$ visão do professor Rogério, da Instituição $\mathrm{B}$, transpareceu que uma disciplina em caráter eletivo talvez suprisse essa demanda. Entretanto, para ambos os professores responsáveis pelas disciplinas, determinados conhecimentos se faziam ausentes da matriz curricular, embora os elementos determinantes desse não lugar institucionalizado não tivessem sido uma questão aprofundada pelos sujeitos. Com seu forte potencial simbólico, tais conhecimentos acabam cativando a comunidade acadêmica como uma possibilidade de "alimentar mais essa Educação Física" (José, docente responsável, Instituição A).

Destaca-se que as práticas circenses são conhecimentos enriquecedores, transversais, com grande potencial educativo e que possibilitam almejar um projeto crítico de educação das sensibilidades, de uma educação estética (BORTOLETO, 2011). Consequentemente, é possível e desejável que o fazer pedagógico da Educação Física possa de fato abraçar esses conhecimentos, considerando suas potencialidades e motivando ao aprofundamento de seus fundamentos, características, determinantes sociais, histórico-culturais e políticos.

Curiosamente, detectou-se que as iniciativas nas duas instituições foram nutridas pela aproximação a outros contextos de produção artística, bem como pelo fato de transitarem naqueles espaços alunos que começavam a se profissionalizar no cenário circense, favorecendo o intercâmbio entre essas instituições e a troca de conhecimentos, processo este extremamente rico e instigante para os docentes e discentes. Cabe salientar que a própria região na qual está localizada a Instituição A tem a presença de muitos grupos de artistas e famílias circenses.

A fala do professor José revela essa situação, ao identificar com clareza que tal inserção não ocorreu ao acaso.

Durante muito tempo, vários anos, a faculdade foi sendo visitada pelo circo. Alguns alunos faziam oficinas, vinham praticar. Eu mesmo fiz parte de um grupo de perna de pau aqui, enfim, houve vários processos. O G. G. era um grupo que sempre teve alguma atividade com circo por conta de pessoas do grupo, de acrobático, palhaço. Algumas pessoas faziam curso no L. (José, docente responsável pela disciplina, Instituição A).

Essas "primeiras rachaduras" de forma muito fértil foram abrindo brechas para que tais contextos começassem gota a gota a ser banhados pela potência criadora e pelo dinamismo que permeiam e atualizam constantemente o universo circense. Saberes plurais e heterogêneos (TARDIF, 2002) e que durante muito tempo foram invisibilizados pela Educação Física, mas que, na contemporaneidade, conforme já se iluminou, tem possibilitado refletir sobre suas interfaces.

Especificamente na Instituição A, verificou-se que já vinha sendo dada certa abertura e aproximação às práticas circenses por meio da prática da Ginástica para Todos (GPT), através de um grupo de pesquisa em ginástica que foi constituído e se mantém ativo até os dias atuais. Esse processo parece ter propiciado a experimentação e mescla dos elementos gímnicos a outras práticas corporais, algo que faz parte dos próprios objetivos e características da GPT, conforme nos atesta Ayoub (2007). Nesse caso, as práticas circenses figuraram inclusive como tema em algumas composições elaboradas por este grupo, apesar da abordagem ainda incipiente.

Embora a incorporação e a legitimação desses conhecimentos tenham sido graduais nas duas IES, infere-se que tais processos de implementação possuem estreita vinculação a um movimento mais amplo de abertura e renovação do campo da Educação Física brasileira que vem ocorrendo desde a década de 1980 (SILVA; BRACHT, 2012). Assim, diferentes 
conhecimentos da cultura corporal, como é o caso da capoeira e de tantas outras práticas corporais, começam a ser olhados com maior rigor e aprofundamento através da historicização dos conhecimentos (METODOLOGIA..., 1992).

Como apontaram Bortoleto e Celante (2011), os cursos de formação inicial em Educação Física têm primado pela diversificação de práticas corporais em seus currículos com diferentes propostas metodológicas, considerando a multiplicidade dos âmbitos de atuação profissional da área (escolas, academias, centros esportivos, projetos sociais, entre outros). Os mesmos autores argumentam que as manifestações em questão fazem parte de um processo de reaproximação da arte circense com a Educação Física, embora tais iniciativas sejam ainda incipientes.

Todavia, especificamente na Instituição A, houve um momento relevante, o qual, considerando o discurso dos sujeitos investigados, caracterizou-se como situação culminante que movimentou a temática do circo, dando visibilidade aos debates. Esse evento foi um seminário de pesquisa ocorrido há alguns anos, oportunidade interessante de troca de conhecimentos, de diálogo entre sujeitos com formações diversas, fomentando ações no âmbito do ensino, da pesquisa e da extensão.

Algo que foi citado pela professora Dori, da Instituição A, e pelo aluno egresso da mesma instituição não poderia passar despercebido: a mudança de nomenclatura da disciplina que surgiu alocada num conjunto de disciplinas eletivas chamadas de "Tópicos Especiais". Essas disciplinas figuravam no currículo justamente para dar conta de temas inovadores, de demandas dos alunos ou mesmo para que cada professor pudesse dar uma abordagem diferente a suas pesquisas. Posteriormente, esse conjunto de disciplinas ganhou um nome específico, "Atividades Circenses e Educação Física". É o que se observa na narrativa da professora:

\begin{abstract}
Eu acho muito interessante porque essa disciplina começou aqui na faculdade como uma eletiva, sem um nome específico de atividades circenses. Ela foi aberta como Tópicos Especiais que é um rol de disciplinas que a graduação abriu para que cada professor pudesse dar o seu enfoque nessas disciplinas sem que realmente ficasse marcada especificamente com um determinado título. [...] Então, institucionalizar essa disciplina com um nome, acho que foi muito importante porque marca um espaço que aqui na faculdade cresce a cada dia que é a questão do circo num contexto mais formal (Dori, docente e ex-coordenadora de curso, Instituição A).
\end{abstract}

Fica evidente como o próprio currículo não é algo neutro, fechado, mas fruto de sua produção contextual e por isso mesmo passível de reconfigurações, negociações que evidentemente não ocorrem sem tensões. Portanto, "o currículo não é um elemento transcendente e atemporal - ele tem uma história, vinculada a formas específicas e contingentes de organização da sociedade e da educação" (MOREIRA; TADEU, 2011, p. 14).

Nota-se que pelo menos quatro aspectos confluíram para que de fato as práticas circenses se fizessem presentes nas matrizes curriculares dos cursos e, como já foi explicitado, adquirissem um espaço legitimado na estrutura curricular, quais sejam:

- a sensibilização pelo tema matizada pelas experiências pedagógicas e artísticas anteriores dos professores responsáveis pelas disciplinas;

- investimentos de diferentes naturezas, abertura institucional e fomento à pesquisa; 
- a proximidade e a troca de conhecimentos com outros contextos acadêmicos ou de produção artística, bem como o intercâmbio entre as IES pesquisadas;

- a demanda dos alunos por temas emergentes na Educação Física.

Especificamente sobre essa questão da abertura que as duas IES, bem como os docentes do curso, deram a esses conhecimentos foi algo a que diferentes sujeitos entrevistados se reportaram. Os achados da pesquisa indicam que esse aspecto foi fundamental, pois contribuiu para que as práticas circenses fossem vistas como relevantes para figurarem nos currículos.

\section{ENTRE PRÁTICAS CIRCENSES E EDUCAÇÃO FÍSICA: OUTRAS TESSITURAS PARA A FORMAÇÃO INICIAL}

Os desafios enfrentados possibilitaram o mapeamento de algumas demandas específicas da formação inicial em Educação Física que surgiram predominantemente de fora para dentro, isto é, impactando os muros da universidade, gerando diferentes desdobramentos. Do mesmo modo, sinalizaram que as práticas circenses vêm ganhando legitimidade nos cursos pesquisados e em tantos outros que temos tido notícias no cenário brasileiro e internacional.

Tal ampliação tem se dado pelo oferecimento das disciplinas específicas, que se configuram como espaços peculiares para a sua experimentação, análise crítica e ressignificação, pelas publicações recentes dos grupos de estudos formados no interior dessas IES, pelos projetos de extensão, seminários, encontros de cunho artístico, oficinas, entre outros.

Apesar do quadro matizado, é prudente indicar que ainda coexistem diferentes níveis de compreensão presentes tanto nos discursos dos docentes como dos alunos, reafirmando a urgência de pesquisas e da busca por alternativas para facilitar a apropriação dos avanços teóricos e epistemológicos da área para o contexto da intervenção pedagógica. São discursos atravessados por muitas lógicas, impregnados por diferentes perspectivas, interesses, valores e contradições, processos nos quais pairam algumas dúvidas quanto à articulação das disciplinas com os documentos analisados (PPP e RI), especificamente no caso da Instituição B, pelo fato de não ter sido acessado este documento.

A relativamente rápida expansão e apropriação desses conhecimentos pela universidade vem acompanhada de carências na ênfase aos aspectos técnicos e procedimentais, materializando alguns equívocos pedagógicos, apesar de interessantes sistematizações. As análises salientam que saberes produzidos fora dos bancos acadêmicos não podem ser desqualificados, como se não fossem portadores de uma metodologia própria, de uma sistematização coerente nos processos de ensino-aprendizado.

Nos casos investigados, a participação efetiva dos docentes e discentes nas ações extensionistas, de ensino e de pesquisa tem contribuído para sua consolidação, até pelas falas enfáticas dos gestores. Esse panorama parece encorajar inclusive os alunos egressos a incorporarem tais práticas nas instituições escolares, projetos, academias de ginástica e tantos outros contextos em que as práticas circenses habitam e transitam na contemporaneidade.

Notou-se a impossibilidade de desvincular as trajetórias individuais dos professores investigados, especialmente aqueles responsáveis pelas disciplinas ligadas à temática circense das suas práticas pedagógicas. Sujeitos encarnados que estabeleceram redes de 
conhecimentos e de atualização muito próprias, provocando deslizamentos de sentidos cristalizados pela Educação Física através de atitudes compromissadas com seus alunos numa relação compartilhada, optando por metodologias inclusivas, inovadoras, para além dos limites e da organização que os tempos e espaços institucionalizados impõem.

Do mesmo modo, compartilharam conhecimentos entre as IES e com outros países, entrelaçando múltiplos contextos de formação, parcerias com artistas profissionais, aproximando realidades em busca de uma Educação Física mais sensível com os sujeitos que ali estão. Portanto, os docentes pesquisados não ficaram "engessados" na rotinização da prática. Ousaram, intercambiaram experiências e deixaram de lado a autoridade do saber acadêmico para se banharem nos saberes da experiência, do cotidiano dos circenses, para os quais a tradição não significa necessariamente imobilismo. São sujeitos históricos que tiveram suas vozes ouvidas e memórias valorizadas na universidade, construindo novos percursos e atualizando "a linguagem circense em seu modo rizomático, múltipla, polissêmica e polifônica” (SILVA; ABREU, 2009, p.181).

Ressalta-se que os processos ora investigados não foram fortuitos, mas sedimentados por ricas histórias de mobilizações, de trajetórias de pesquisa e da busca pela construção de sólidos conhecimentos. Conquistas estas num movimento de diálogo, mas também de duras resistências enfrentadas num solo árido da tradição esportivista da Educação Física pouco permeável a mudanças.

Nesse ensejo, todas as práticas corporais têm suas potencialidades pedagógicas. Talvez umas mais outras menos porque estão obviamente assentadas em raízes históricas diferentes e pressupostos filosóficos que não se coadunam. Volta-se a insistir que os aspectos citados não são de exclusividade das práticas circenses. O risco, a ousadia e a contradição plasmada na capacidade de referendar o espetacular do humano através do simbolismo que favorece 0 trabalho pedagógico. Obviamente, tudo vai depender dos sujeitos que operam tais processos.

Enfim, espera-se que esta pesquisa possa contribuir com os processos de estruturação curricular das práticas circenses, sem, entretanto, colocá-las como porta salvadora para a desequilibrada distribuição de conhecimentos que perfazem os currículos. Nada resolveria trocar um conhecimento por outro, mas valorizar as produções das diferentes culturas que adentram os espaços educativos. Talvez, uma noção dinâmica de currículo favorecedora de encontros potentes pautados em outras formas de organização dos conhecimentos para além de disciplinas isoladas, subvertendo o modelo racional das áreas disciplinares, seja capaz de contemplar a multiplicidade, transversalidade e ousadia da linguagem circense.

Mais do que explicar, intencionou-se refletir sobre essas possibilidades de singularização que mesclaram a riqueza, o simbolismo das cores, os sons, os gestos, a expressividade e a poética das práticas circenses, algo que parece ter reinventado aproximações entre educação, arte e corpo. Dinamicidade e pluralidade sempre presentes nas tessituras produzidas por este, ou talvez, através desses múltiplos "teares" da formação inicial em Educação Física.

\section{REFERÊNCIAS}

ABRAHÃO, Sergio R. Valoración de las actividades circenses en la formación de profesorado de Educación Física: una propuesta para la transformación social en la escuela. 2011. Tese (Doutorado) - Facultat de Formació del Porfessorat, Universidad de Barcelona, 2011. 
AYOUB, Eliana. Ginástica geral e educação física escolar. 2. ed. Campinas, SP: Editora da Unicamp, 2007.

BOLTON, Reg. Why circus works: how the values and structures of circus make it a significant developmental experience for young people. 2004. Tese (Doutorado) - Universidade de Murdoch, Perth, 2004.

BORTOLETO, Marco A. C. A perna de pau circense - o mundo sob outra perspectiva. Motriz, Rio Claro, v. 9, n. 3, p. 125-133, set./dez. 2003.

BORTOLETO, Marco A. C. Atividades circenses: notas sobre a pedagogia da educação corporal e estética. Cadernos de Formação RBCE, Florianópolis, p. 43-55, jul. 2011.

BORTOLETO, Marco A. C.; CELANTE, Adriano R. O ensino das atividades circenses no curso de Educação Física: experiências na universidade pública e privada. In: PEREIRA, Elisabete M. A.; CELANI, Gabriela; GRASSI-KASSISSE, Dora M. (Org.). Inovações curriculares: experiências no ensino superior. Campinas, SP: FE/UNICAMP, 2011, v.1, p.178-190.

BORTOLETO, Marco A. C.; PINHEIRO, Pedro H. G. G.; PRODÓCIMO, Elaine. Jogando com o circo. Jundiaí, SP: Fontoura, 2011.

BRASIL. Ministério do Esporte. Secretaria Nacional de Esporte Educacional. Diretrizes do Programa Segundo Tempo. Brasília, 2011. Disponível em: <http://www.esporte.gov.br/segundotempo $>$. Acesso em: 24 abr. 2015.

DENZIN, Norman K.; LINCOLN, Yvonna S. O planejamento da pesquisa qualitativa: teorias e abordagens. Porto Alegre: Artmed, 2006.

DUPRAT, Rodrigo M. Atividades circenses: possibilidades e perspectivas para a educação física escolar. 2007. Dissertação (Mestrado) - Faculdade de Educação Física, Universidade Estadual de Campinas, Campinas, 2007.

DUPRAT, Rodrigo M.; GALLARDO, Jorge S. P. Artes circenses no âmbito escolar. ljuí: Ed. Unijuí, 2010.

DUPRAT, Rodrigo M.; DARIDO, Suraya C. Uma possibilidade de organização curricular do conteúdo circo nos anos iniciais do Ensino Fundamental. Motriz, Rio Claro, v. 17, n. 1 p. S1-S523, jan./mar. 2011. supl. I.

FERNANDES, Rita de C. As atividades circenses na formação inicial em educação física: experiências curriculares em ação na universidade pública e privada. Caderno de Resumos dos Seminários de Teses e Dissertações em Andamento, Campinas, v. 1, p. 79, 2013.

FERNANDES, Rita de C. Do tecido à lona: as práticas circenses no tear da formação inicial em educação física. 2014. Tese (Doutorado) - Faculdade de Educação, Universidade Estadual de Campinas, Campinas, 2014.

FLICK, Uwe. Introdução à pesquisa qualitativa. 3. ed. Porto Alegre: Artmed, 2009.

FODELLA, Patrick. Les arts du cirque a l'ecole: Dossier arts du cirque. Revista EPS1, Paris, n. 97, 2000.

HAUFFE, Mirian K.; GÓIS JUNIOR, Edivaldo. A Educação Física e o funâmbulo: entre a arte circense e a ciência (século XIX e início do século XX). Revista Brasileira de Ciências do Esporte, Florianópolis, v. 36, n. 2, p. 547-559, abr.jun. 2014.

INVERNÓ, Josep. Circo y educación física: otra forma de aprender. Barcelona: INDE, 2003.

JOVCHELOVITCH, Sandra; BAUER, Martin. Entrevista narrativa. In: BAUER, Martin; GASKELL, George. Pesquisa qualitativa com texto, imagem e som: um manual prático. 10. ed. Petrópolis, RJ: Vozes, 2012. p. 90-113.

KINCHELOE, Joe L. Para além do reducionismo: diferença, criticalidade e multilogicidade na bricolagem e no pós-formalismo. In: PARASKEVA, João (Org.). Currículo e multiculturalismo.

Lisboa: Pedago, 2006. p. 63-93. 
LOPES, Alice C.; MACEDO, Elizabeth. Teorias de currículo. São Paulo: Cortez, 2011.

LUDKE, Menga; ANDRÉ, Marli. Pesquisa em educação: abordagens qualitativas. São Paulo: EPU, 1986. METODOLOGIA do ensino da educação física. São Paulo: Cortez, 1992.

MOREIRA, Antônio F. B.; TADEU, Tomaz. Sociologia e teoria crítica do currículo: uma introdução. In: MOREIRA, Antônio F. B.; TADEU, Tomaz (Org.). Currículo, cultura e sociedade. 12. ed. São Paulo: Cortez, 2011. p. 13-47.

MCCUTCHEON, Sharon. Negotiating identity through risk: a community circus model for evoking change and empowering youth. 2003. Dissertação (Mestrado) - Faculty of Arts, Charles Sturt University, Bathrust, New South Whales, 2003.

ONTAÑÓN, Teresa. Atividades circenses na educação física escolar: equilíbrios e desequilíbrios pedagógicos. 2012. Dissertação (Mestrado) - Faculdade de Educação Física, Universidade Estadual de Campinas, Campinas, 2012.

ONTAÑÓN, Teresa; DUPRAT, Rodrigo M.; BORTOLETO, Marco A. C. Educação física e atividades circenses: o "estado da arte". Movimento, Porto Alegre, v. 18, n. 2, p. 149-168, abr./jun. 2012.

PARANÁ. Secretaria de Estado da Educação do Paraná. Diretrizes curriculares da educação básica: Educação Física. Curitiba, 2008. Disponível em: <http://www.educadores.diaadia.pr.gov.br/ arquivos/File/diretrizes/dce_edf.pdf>. Acesso em: 2015.

PRICE, Christopher. Circus for schools: bringing a circo arts dimension to physical education. PHEnex Journal, Ottawa, v. 4, n. 1, 2012.

ROCHA, Décio; DAHER, Maria D. C.; SANT'ANNA, Vera L. de A. A entrevista em situação de pesquisa acadêmica: reflexões numa perspectiva discursiva. Polifonia, Cuiabá, v. 8, n. 8, 2004.

SANTOS, Cristiane C. G. et al. A linguagem corporal circense: interfaces com a educação e a atividade física. São Paulo: Phorte, 2012.

SILVA, Ana M.; DAMIANI, lara R. As práticas corporais na contemporaneidade: pressupostos de um campo de pesquisa e intervenção social. In: SILVA, Ana Marcia; DAMIANI, lara R. (Org.). Práticas corporais: gênese de um movimento investigativo em Educação Física. Florianópolis: Nauemblu, 2005. p. 17-27.

SILVA, Cinthia L. Vivência de atividades circenses junto a estudantes de educação física: reflexões sobre educação física no ensino médio e tempo livre. Revista Licere, Belo Horizonte, v. 12, n. 2, p.117, jun. 2009.

SILVA, Ermínia; ABREU, Luís A. de. Respeitável público... o circo em cena. Rio de Janeiro: Funarte, 2009.

SILVA, Mauro S.; BRACHT, Valter. Na pista de práticas e professores inovadores na educação física escolar. Kinesis, Santa Maria, v. 30, n. 1, p. 80-94, jan.jjun. 2012.

SILVA, Tomaz Tadeu. Documentos de identidade: uma introdução às teorias do currículo. Belo Horizonte: Autêntica, 2007.

SOARES, Carmem L. Imagens da educação no corpo: estudo a partir da ginástica francesa no século XIX. 2. ed. Campinas: Autores Associados, 2002.

SOARES, Carmen L. Da arte e da ciência de movimentar-se: primeiros momentos da ginástica no Brasil. In: DEL PRIORE, Mary; MELO, Vitor A. de (Org.). História do esporte no Brasil: do Império aos dias atuais. São Paulo: Editora da Unesp, 2009. v. 1, p. 133-178.

TARDIF, Maurice. Saberes docentes e formação profissional. Petrópolis, RJ: Vozes, 2002.

TUCUNDUVA, Bruno B. P.; PELANDA, Pedro. E. L. CIRCOFITNESSQ: proposta pedagógica de trabalho com as acrobacias das atividades circenses. In: TOLEDO, Eliana; AYOUB, Eliana; BORTOLETO; Marco A. C.; PAOLIELLO, Elizabeth (Org.). Fórum internacional de ginástica geral. Campinas: FEF/Unicamp, 2012. p. 319-325. 